\title{
Large-scale physical modelling study of a flexible barrier under the impact of granular flows
}

\author{
Dao-Yuan Tan, Jian-Hua Yin, Wei-Qiang Feng, Jie-Qiong Qin, and Zhuo-Hui Zhu \\ Department of Civil and Environmental Engineering, The Hong Kong Polytechnic University, \\ Hung Hom, Kowloon, Hong Kong, China \\ Correspondence: Jian-Hua Yin (cejhyin@polyu.edu.hk)
}

Received: 6 May 2018 - Discussion started: 18 June 2018

Revised: 3 September 2018 - Accepted: 11 September 2018 - Published: 2 October 2018

\begin{abstract}
Flexible barriers are being increasingly applied to mitigate the danger of debris flows. However, how barriers can be better designed to withstand the impact loads of debris flows is still an open question in natural hazard engineering. Here we report an improved large-scale physical modelling device and the results of two consecutive large-scale granular flow tests using this device to study how flexible barriers react under the impact of granular flows. In the study, the impact force directly on the flexible barrier and the impact force transferred to the supporting structures are measured, calculated, and compared. Based on the comparison, the impact loading attenuated by the flexible barrier is quantified. The hydro-dynamic approaches with different dynamic coefficients and the hydro-static approach are validated using the measured impact forces.
\end{abstract}

\section{Introduction}

Debris flows, as one of the most disastrous natural geohazards, have caused destructive damage to human lives and their habitations in many countries such as the USA, Japan, and China (Takahashi, 2014; Hungr, 1995; Ishikawa et al., 2008; Su et al., 2017). In a mountainous area where a large amount of loose sediment is present, multiple debris flows can occur under intensive heavy rains (Xu et al., 2012; Yagi et al., 2009; Chen et al., 2017). Protective systems such as concrete check dams are usually installed in areas threatened by debris flows to prevent the damage (Santi et al., 2011). Recently, researchers have found that flexible barriers, which were firstly used in rockfall prevention, are effective at trapping debris flows (Canelli et al., 2012; Wendeler et al., 2007;
Cui et al., 2015; Hu et al., 2006; Kwan et al., 2014). Compared to conventional rigid concrete check dams, flexible barriers have a few obvious advantages: they are economical, efficient in impact energy absorption, easy to be installed, and adaptable to various terrains (Ashwood and Hungr, 2016; Wendeler and Volkwein, 2015).

Physical modelling has been widely used in geotechnical engineering research because of its excellent controllability in testing conditions and good reliability of testing results (Paik et al., 2012; Wendeler et al., 2006; Bugnion et al., 2012; DeNatale et al., 1999). Scaling is a key parameter in experiment design for studying debris flows because it can affect the interaction between particles in a granular flow. In miniaturized debris flows generated in small-scale tests, the effects of viscous shear resistance, friction, and cohesion are over-represented, whereas the effects of excess pore-fluid pressure, which are generated by debris dilation or contraction, are under-represented (Iverson, 2015). With appropriate dimensional analysis, laboratory tests can be used to qualitatively study behaviour of the interaction between a debris flow and a flexible barrier (Wendeler and Volkwein, 2015; Wendeler et al., 2018; Song et al., 2017). However, the dynamic behaviour of different barrier components of a prototype flexible barrier and the stiffness of the flexible ring nets applied in the field are difficult to reliably replicate in miniaturized physical models (Wendeler et al., 2018). Considering the scale effects, some researchers use large-scale physical models or field-scale experimental sites to study debris flows (DeNatale et al., 1999; Wendeler, 2008; Paik et al., 2012; Bugnion et al., 2012; Iverson, 2015). WSL (2010) conducted a series of full-scale tests to study the interaction between multiple debris flows and a prototype flexible barrier. Large- 
scale physical modelling tests are also selected by the authors to investigate the interaction between a flexible barrier and dry granular flows.

A typical flexible barrier usually consists of two main components: a flexible ring net and supporting structures (supporting posts stretching the flexible barrier, strand cables and foundations supporting the posts). The impact loading from a debris flow is firstly attenuated by the flexible ring net with large deformation and then transfers to the cross-tension cables, which form the outline frame and stretch the ring net, and finally to the posts and the supporting cables. Generally, energy-dissipating elements are installed on the supporting cables to reduce load peaks transferred to the foundations (Volkwein, 2014; Wendeler et al., 2018). In this study, energy-dissipating elements are replaced by large-capacity tension link transducers to accurately measure the impact loading transferred to the supporting structures.

Impact loading estimation is key to the design of a flexible barrier for debris flow mitigation (Volkwein et al., 2011). Wendeler et al. (2018) concluded that the static pressure on the flexible barrier is dominant and gradually increases with time during the impact process based on the observations of field tests. Simple approaches are commonly used by designers in impact loading estimation because they require only a few parameters in the calculation. There are two widely accepted simple approaches: the hydro-dynamic approach and the hydro-static approach. The hydro-dynamic approach is based on momentum conservation. In this approach, the impact period is taken as an ideal flow with a uniform velocity impacting the barrier and deviating along the vertical direction. The impact loading is calculated from the momentum change of the decelerated debris flow during the impact (Hungr et al., 1984; Armanini, 1997). The hydro-static approach, on the other hand, is calculated from the earth pressure of deposited debris (Rankine, 1857). Both approaches adopt empirical coefficients to reach a good accuracy in predicting real cases.

The estimation of impact force with the hydro-dynamic approach (Hungr et al., 1984) is expressed as follows:

$F_{\text {calculated }}=\alpha \rho_{\text {bulk }} v_{0}^{2} h w$,

where $\rho_{\text {bulk }}$ is the bulk density of a debris flow; $v_{0}$ is the velocity of the debris flow; $h$ is the height of the debris flow; $w$ is the width of the debris flow, which is normally represented by the width of the flowing channel; and $\alpha$ is the dynamic coefficient. Hungr et al. (1984) proposed a value of 1.5. Wendeler (2008) suggested a value of 0.7 for mud flows and 2.0 for granular flows, considering the flexibility and permeability of flexible barriers. Canelli et al. (2012) proposed a range of values from 1.5 to 5 .
The hydro-static approach (Lichtenhahn, 1973; Armanini, 1997) is given as follows:

$F_{\text {calculated }}=0.5 \kappa \rho_{\text {bulk }} g h_{\text {deposit }}^{2} w$,

where $\kappa$ is the static coefficient, which is suggested as 1.0 in the calculation (Kwan and Cheung, 2012; Wendeler et al., 2018). $g$ is gravitational acceleration, and $h_{\text {deposit }}$ is the deposition height of the debris flow.

Wendeler et al. (2018) proposed a stepwise load model to describe the impact pressures on the flexible barrier during the impact process. In this model, the hydro-dynamic approach with the dynamic coefficient of 0.7 for mud flows and 2.0 for granular flows and the hydro-static approach with the static coefficient of 1.0 are used to calculate the dynamic impact loading from the moving debris flow and the earth pressure from the static debris deposition, respectively. The whole impact process was divided into three impact stages: the initial impact, the filling stage, and the overflow stage. In the initial impact stage, there was only dynamic impact loading on the flexible barrier. In the filling stage, the loading combination on the flexible barrier contained both the dynamic impact loading and the static earth pressure. In the overflow stage, only the static loading from the deposited debris and the overflowed debris flow were exerted on the flexible barrier. This method was verified by the tensile forces on the supporting cables of a flexible barrier in the field tests.

However, the interaction between a flexible barrier and multiple granular flows is not fully understood. Values of the suggested coefficients used in the hydro-dynamic and hydrostatic approaches need to be further verified. The efficiency of loading reduction by flexible barriers has not been accurately quantified. Therefore, further research on the impacts of debris flows on a flexible barrier is urgently required.

This paper aims to study the motions of multiple granular flows and the performance of a flexible barrier under the impact of granular flows with large-scale physical modelling tests. The data from well-arranged transducers and high-speed cameras in the debris flow impact tests are presented and analysed in this paper. The motions of two consecutive granular flows are described in detail. The impact forces on the flexible ring net and the supporting structures of the flexible barrier are measured. Using the measured results, the contribution of flexibility to impact loading reduction is quantified, and simple approaches with different coefficients for impact force estimation are verified.

\section{Experiment setup and instrumentation}

\subsection{Description of the experiment apparatus}

A testing device is built in the Road Research Lab of The Hong Kong Polytechnic University with a length of $9.5 \mathrm{~m}$, a height of $8.3 \mathrm{~m}$, and a width of $2 \mathrm{~m}$. The view of the experiment setup is plotted in Fig. 1. This facility can be divided 
(a)

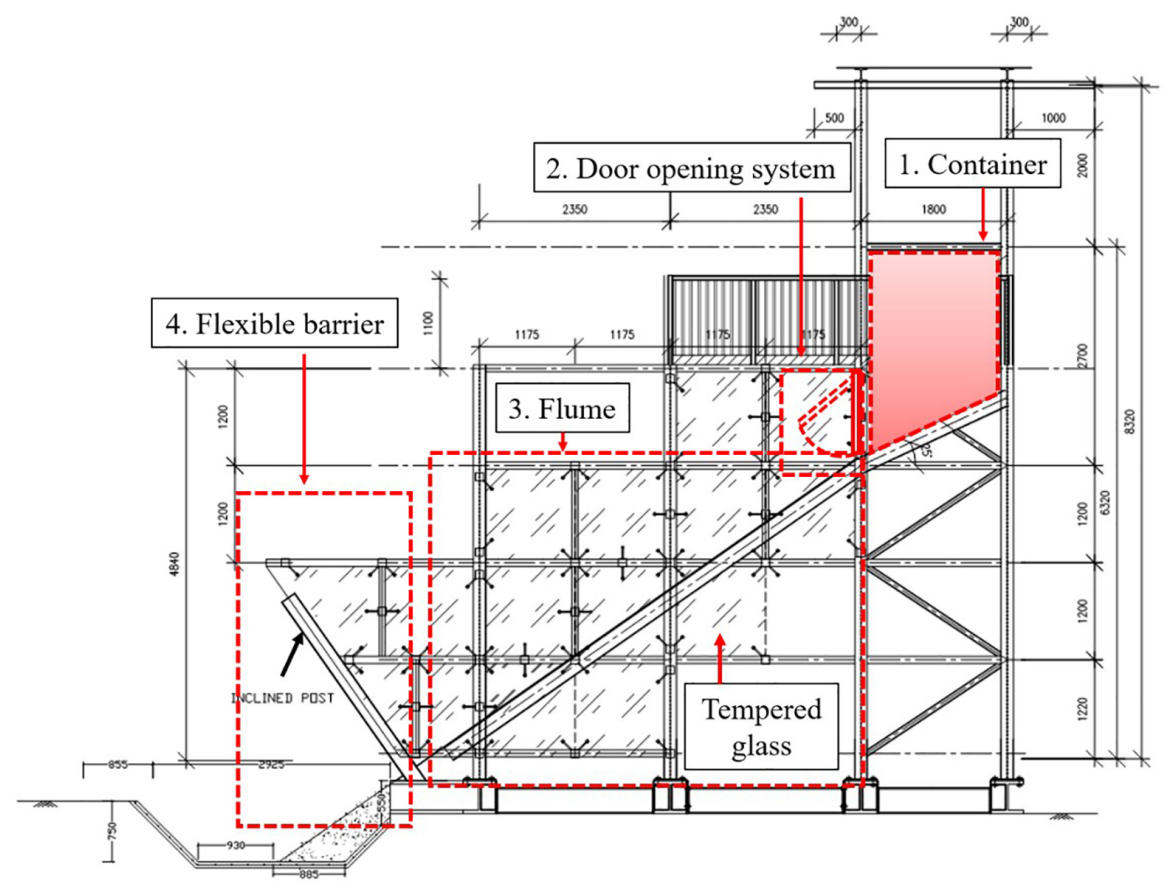

(b)

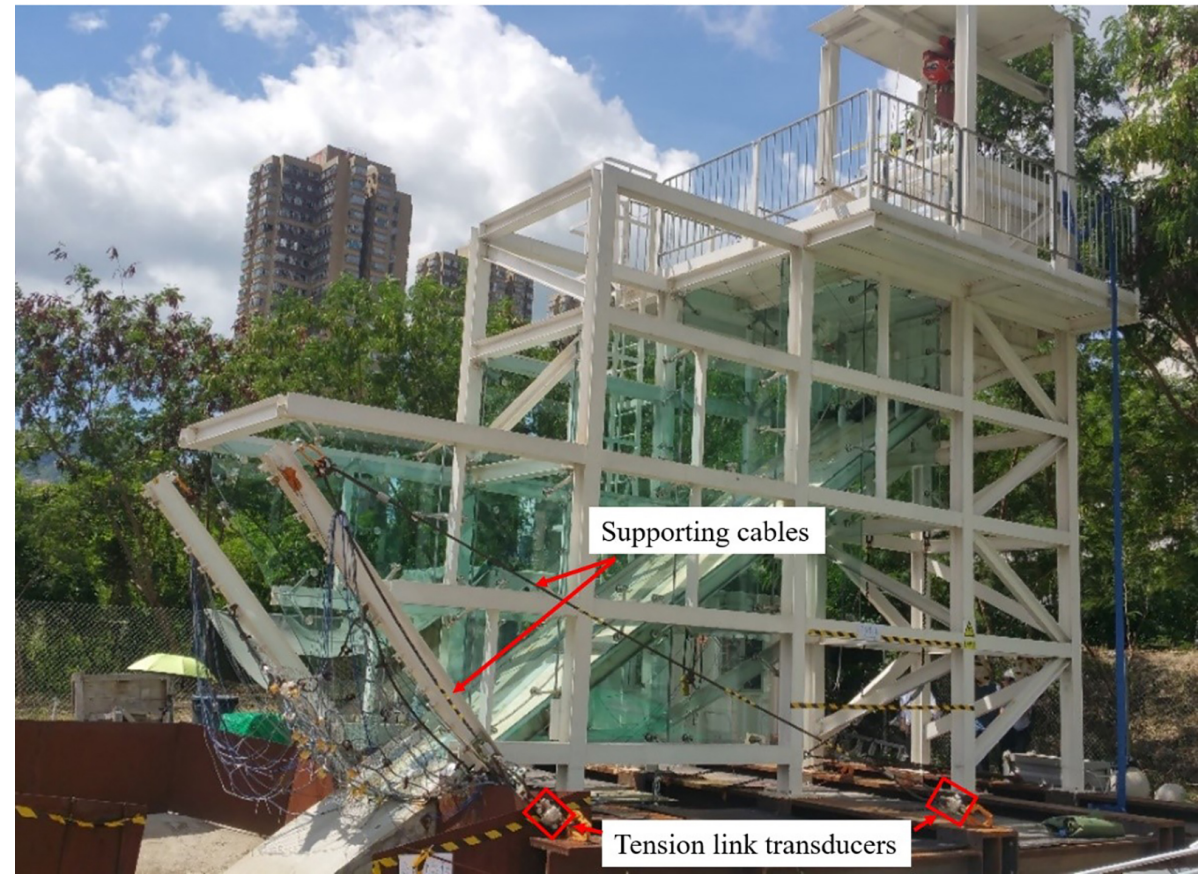

Figure 1. (a) Side view of a large-scale physical model design (unit: $\mathrm{mm}$ ) and (b) photograph of the physical modelling facility constructed at a site in Hong Kong.

into four main components: (i) a reservoir with the capacity of $5 \mathrm{~m}^{3}$ at the top of the device, (ii) a novel quick flip-up dooropening system at the front vent of the reservoir, (iii) a prototype flexible barrier with supporting posts and cables, and (iv) a flume linking the reservoir and the flexible barrier. The prototype flexible barrier with a width of $2.48 \mathrm{~m}$ is made up of steel rings with a diameter of $300 \mathrm{~mm}$ (ROCCO 7/3/300, Geobrugg), which are commonly used in rockfall mitigation 


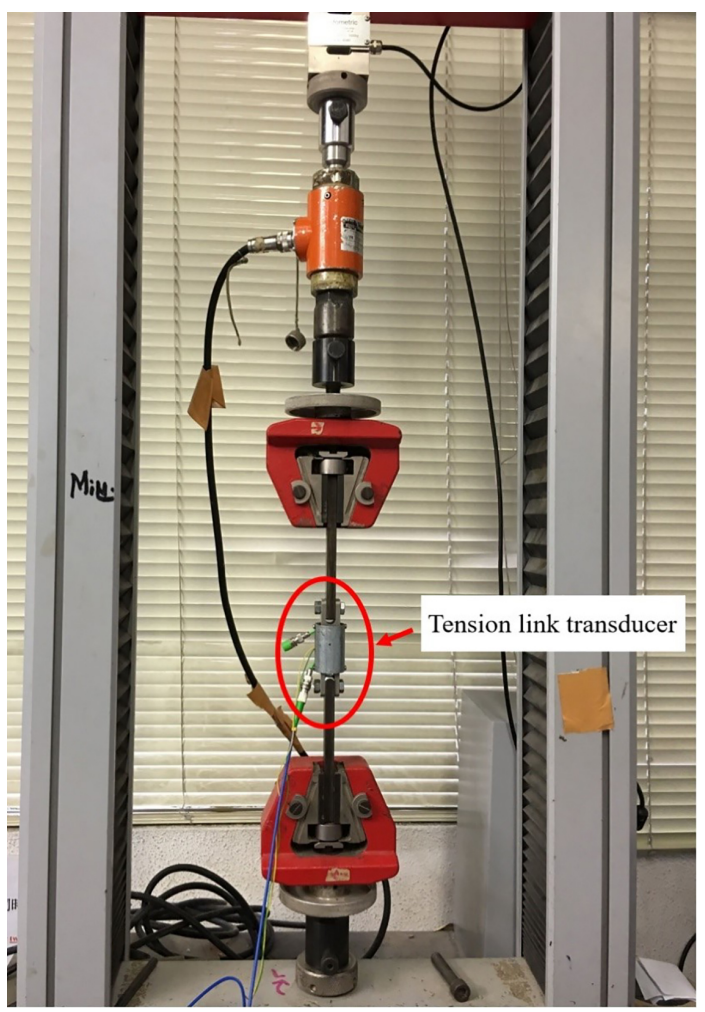

Figure 2. Calibration of a tension link transducer.

in Europe and Hong Kong. This ring net is covered by a flexible secondary net with a mesh size of $50 \mathrm{~mm}$ to provide a high trapping rate for the granular flows. Two parallel posts that can rotate in the plane of impact are installed to stretch and support the ring net, and each post is supported by two inclined strand cables. The flume has a length of $7 \mathrm{~m}$, an inner width of $1.5 \mathrm{~m}$, and an inclination angle of $35^{\circ}$. Side walls of the flume are made up of tempered glass to provide a clear observation of the generated granular flows and their interactions with the flexible barrier. Based on the parameters of the large-scale physical model built by United States Geological Survey (USGS; Iverson et al., 2010; Iverson, 2015), the physical model built at The Hong Kong Polytechnic University (PolyU model) can be regarded as a large-scale physical model because it has similar dimensional parameters with respect to the USGS debris flow flume. Specifically, the capacity of testing material is $5 \mathrm{~m}^{3}$ in the PolyU model compared to $10 \mathrm{~m}^{3}$ in the USGS flume, and the width of the flume is $1.5 \mathrm{~m}$ in the PolyU model compared to $2 \mathrm{~m}$ in the USGS flume. Even though the length of the flume in the PolyU model is much shorter than the length of the USGS flume (7 m compared to $95 \mathrm{~m}$ ), the flume in the PolyU model is sufficient to generate debris flows with dynamic parameters and impact energy similar to real cases. In the trial tests, the generated watery flood can reach a velocity higher than $8 \mathrm{~m} \mathrm{~s}^{-1}$ while flowing down. (a)

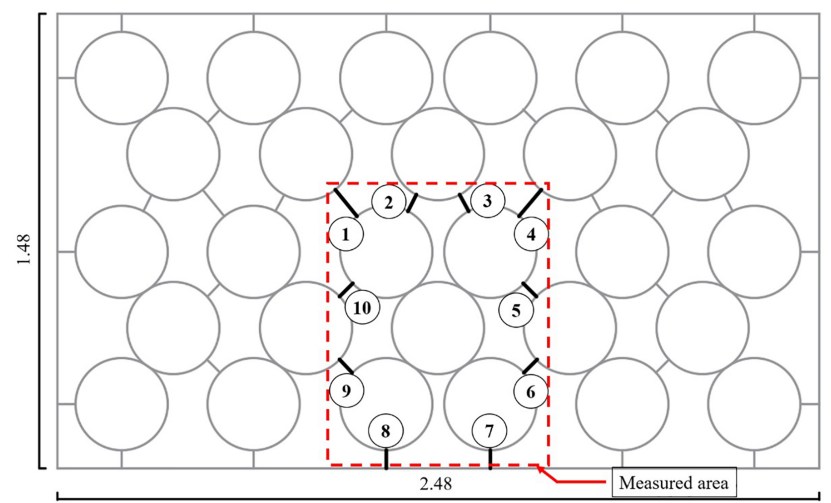

(b)

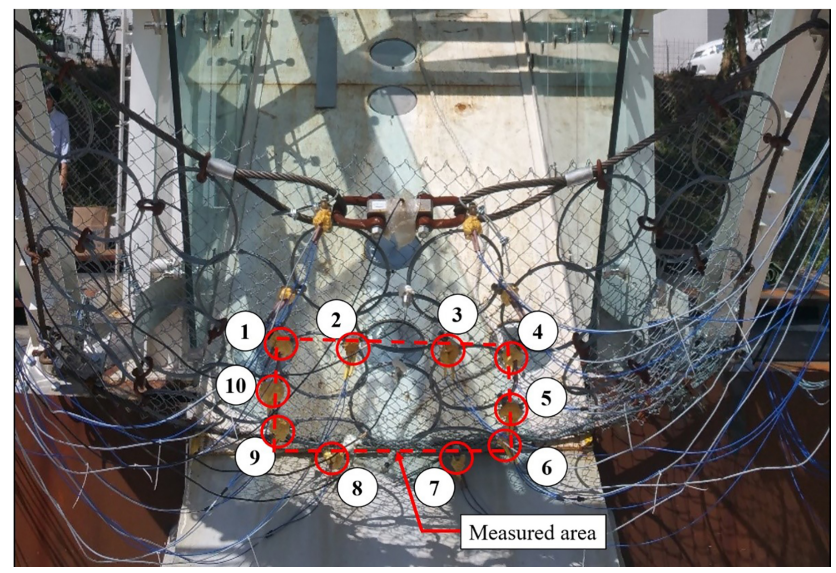

Figure 3. (a) Schematic diagram of a flexible barrier and (b) front view of the flexible barrier with numbered tension link transducers between rings and the measured area in the physical model (unit: $\mathrm{m}$ ).

\subsection{Instrumentation}

To monitor the performance of a flexible barrier under the impact of granular flows, this device is instrumented with a well-arranged high-frequency measurement system. Two types of transducers are installed on the flexible protection system: mini tension link transducers and high capacity tension link transducers. The mini tension link transducers were calibrated in the soil laboratory with a maximum loading of $20 \mathrm{kN}$. The calibration is plotted in Fig. 2. Those transducers are installed on the flexible ring net to measure the impact force on the flexible ring net directly. Specifically, the central area of the flexible ring net, which consists of five connected rings, is separated from the main net and reconnected to the neighbouring rings by 10 mini tension link transducers. Figure 3 presents the measured central area and the arrangement of all the mini tension link transducers on the flexible ring net. The high capacity tension link transducers with a certified capacity of $50 \mathrm{kN}$ are installed on the supporting cables of the posts (see Fig. 1b). A data logger with the capability of sampling 48 transducers at $1000 \mathrm{~Hz}$ simultaneously is used to 
Table 1. Main properties of aggregate used in the test.

\begin{tabular}{lr}
\hline Main properties & Values \\
\hline The total volume of aggregate in test 1 and test $2\left(\mathrm{~m}^{3}\right)$ & 4 \\
Particle diameters $(\mathrm{mm})$ & $15-30$ \\
Internal friction angle $\left(^{\circ}\right)$ & 36 \\
Interface friction angle $\left(^{\circ}\right)$ (between aggregate and painted steel plate) & 28 \\
Bulk density $\left(\mathrm{kg} \mathrm{m}^{-3}\right)$ & 1600 \\
\hline
\end{tabular}

collect the data of all transducers. Two high-speed cameras capable of capturing a resolution of $1024 \times 768$ pixels at a sampling rate of 1000 frames per second are used to capture the motions of the granular flows and the deformation of the flexible barrier under impact. One high-speed camera is located at the right side of the barrier, and the other one is set in front of the barrier. The impact velocity of the debris flow was measured from continuous photographs taken by the side-view high-speed camera. To increase the accuracy of the measurement, two measures were taken: firstly, we set the location and the shooting angle of the side-view highspeed camera very carefully to make sure that the camera was perpendicular to the transparent side wall of the flume; secondly, the velocity was determined from the average velocities of five individual particles measured from five continuous photographs before the impact with the assistance of the reference lines attached to the flume.

\subsection{Experiment material and procedures}

The sample of material used in the tests is plotted in Fig. 4, and their properties are listed in Table 1 . The bulk density of the aggregate is determined from the loose dry bulk density according to ASTM C29/C29M-17a (ASTM, 2017) before the tests. The internal friction angle of the aggregate, which is regarded as having the same value with the angle of repose, is measured by the pouring tests introduced by Miura et al. (1997) and Zhou et al. (2014). The interface friction angle is determined by the tilting plane method introduced by Hutter and Koch (1991) and Zhou et al. (2014). Two consecutive tests, named test 1 and test 2 , were conducted using the same granular material. In test 1 , the granular flow travelled via the flume and impacted an empty flexible barrier, while in test 2 the granular flow moved on the upper surface of the deposition in test 1 to simulate the second surge in multiple flows. The progress of each test is described as follows. At the beginning of the test, the door was flipped up in less than $0.5 \mathrm{~s}$ with the help of a fast door-opening system to generate a uniform granular flow. The data logger started to obtain data several seconds before the triggering of the granular flow to obtain initial values of all the transducers. Simultaneously, the high-speed cameras started to capture the motion of the granular flow and its interaction with the flexible barrier during the impact.

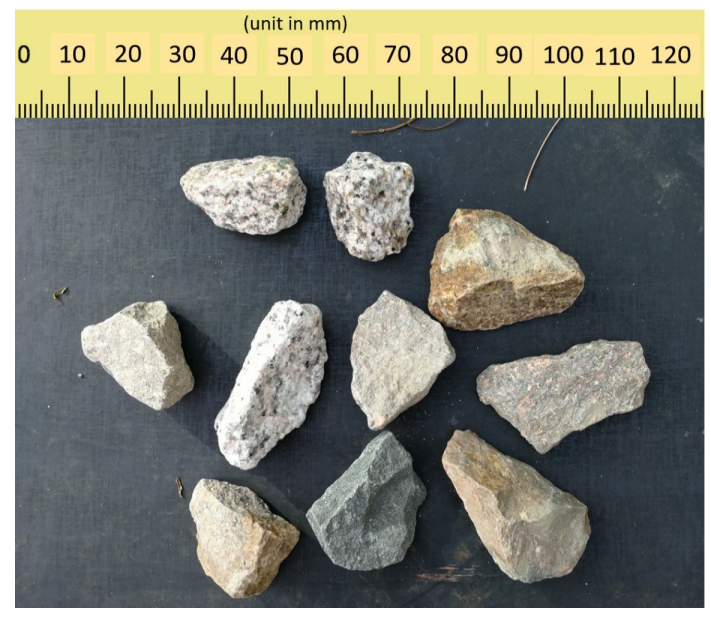

Figure 4. Aggregate samples in the granular flow impact tests (unit: $\mathrm{mm}$ ).

\section{Test results}

\subsection{Motion and impact of granular flow in test 1}

In test 1 , the initial time of the impact was readjusted to $0 \mathrm{~s}$ in all plotted data and selected video frames, and the negative value of time represents the moment before the interaction. By tracking the motion of the granular flow with high-speed cameras, the speed of the granular flow was $5 \mathrm{~m} \mathrm{~s}^{-1}$, which was relatively low compared with the measured velocities from 2 to $12 \mathrm{~m} \mathrm{~s}^{-1}$ in the literature (Arattano and Marchi, 2005; Prochaska et al., 2008; Berti et al., 1999). The deposition height of the granular flow and the maximum horizontal deformation of the flexible barrier at different times are measured from the profiles of the granular flow in photographs taken by the side-view high-speed camera during the impact period (see Fig. 5). It can be observed from Fig. 5 that the front portion of the granular flow shot up, impacted the barrier directly, and was deposited as a wedge-shaped dead zone at the bottom of the flexible barrier from 0 to $1.0 \mathrm{~s}$. The following granular flow climbed on the top surface of the previous stationary deposition, impacted the flexible barrier, and was deposited behind the barrier layer by layer. After $1.0 \mathrm{~s}$, the following granular front was deposited behind the deposition wedge. It is worth noting that the tensile force on the net 


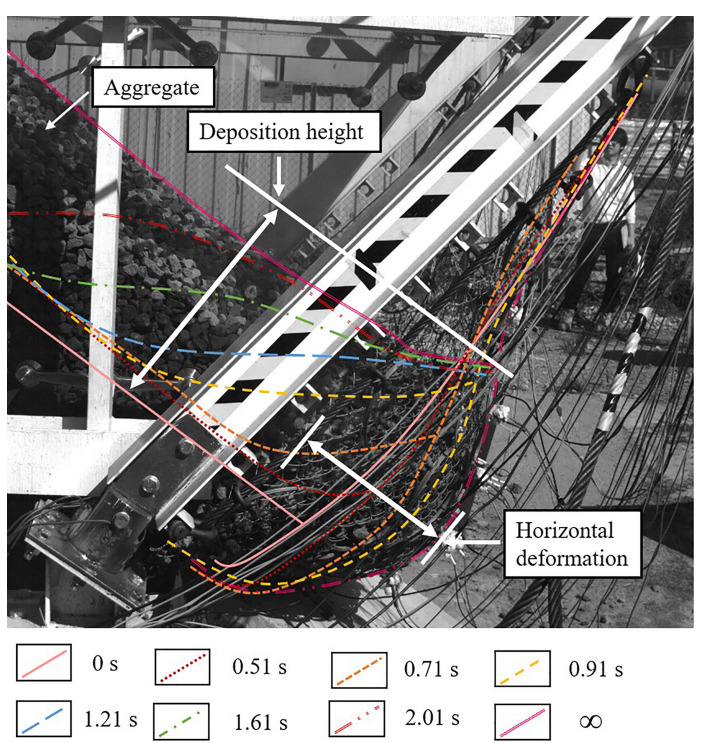

Figure 5. Side profiles of deposited aggregate at different times in test 1 .

keeps increasing even as the deposition height of the granular flow reaches the maximum value. This phenomenon indicates that the granular flow can continuously exert impact pressure on the flexible barrier via the deposition wedge. The measured deposition height, the maximum horizontal deformation, and the tensile force history of transducer 1's change over time are plotted in Fig. 6. It can be seen that the deposition height of the trapped aggregate rises almost linearly with time and reaches $0.82 \mathrm{~m}$ at the time of $1.0 \mathrm{~s}$, and the horizontal deformation of the barrier increases from an initial value of 0.26 to $0.48 \mathrm{~m}$ at the time of $1.0 \mathrm{~s}$.

\subsection{Impact loading analysis in test 1}

Tensile forces recorded by the mini tension link transducers between rings are plotted in Fig. 7. Signals of the transducers have some noise due to the intensive impacts from thousands of particles during the impact period. Thus, trend lines are added into those figures to clarify the changes of tensile forces. A gradual rise of static load and two dynamic impact peaks are observed in the signals of most transducers. The first impact peak occurred at the beginning of the impact, and the second impact peak appeared at the end of the impact. These two peaks are much smaller than the accumulated static load. It is indicated that the dynamic load and the static load co-existed in the impact process, and the static load was dominant. The loading situations of the flexible barrier in our study fit well with the observations of the field tests by Wendeler et al. (2018) that the impact loadings on the supporting ropes increase gradually over time during the impact process. Since the dynamic loading due to the oncoming debris fronts is nearly constant, they concluded that the increase of the impact loading is mainly attributable to the in- cremented debris deposition. Besides, transducers connected to the bottom cross-tension cable (transducer 7 and transducer 8) show negative values, which indicates that they were compressed in the impact process. Figure 8 presents typical frames recorded by the side-view camera and the front-view camera combined with the signal from transducer 1 . From this figure, it can be seen that the first dynamic impact peak came from the direct impact of the first debris front on the flexible barrier, and the gradual increase of the static load was caused by the deposition of the aggregate. With the growth of the deposition zone, the impact loading of the following granular flow was finally fully resisted by the deposition cushion. Afterwards, only static earth pressure of the deposition acted on the flexible barrier.

\subsection{Motion of granular flow in test 2}

The second granular flow was triggered after test 1 to simulate the second flow in a multiple-debris-flow event. In test 2 , the granular flow travelled on the top surface of the deposition in test 1 and came to rest without reaching the net. The motion of the granular flow in test 2 is plotted in Fig. 9. In that figure, the initiated time of the granular flow is readjusted to $0 \mathrm{~s}$. It can be found that the granular flow had a thick front when it was first triggered, and then the thickness kept decreasing during movement. Based on the recording of the side-view camera, the side view of depositions in the two tests and the velocity change of the granular flow with the flowing distance in test 2 are plotted in Fig. 10. The thickness and velocity of the front reduced dramatically with the increase of the moving distance and finally stopped $0.7 \mathrm{~m}$ before the flexible barrier. Correspondingly, neither impact force nor deformation increment of the flexible barrier was recorded by the transducers or the high-speed cameras. The reason for the flow stopping before the flexible barrier is the large basal friction of the rough interface between the moving granular flow and the deposition and the low fluidity of the dry granular flow. The multi-flow tests show that the impact from the debris front that arrived later can be attenuated or eliminated by the resistance from the deposition of the previous debris flow in a multiple-debris-flow event.

\section{Data analysis}

\subsection{Direct measurement of the impact force on the flexible barrier}

As mentioned above, the central area is separated from the main ring net and reconnected to neighbouring net rings by mini tension link transducers. Two assumptions are made to simplify the measurement of the impact loading on a flexible ring net. The deformation of the ring net is assumed similar to a membrane, and the deformation in the measured area is assumed cone symmetric. Based on the assumptions, the loading situation in the cross section of the measured area 


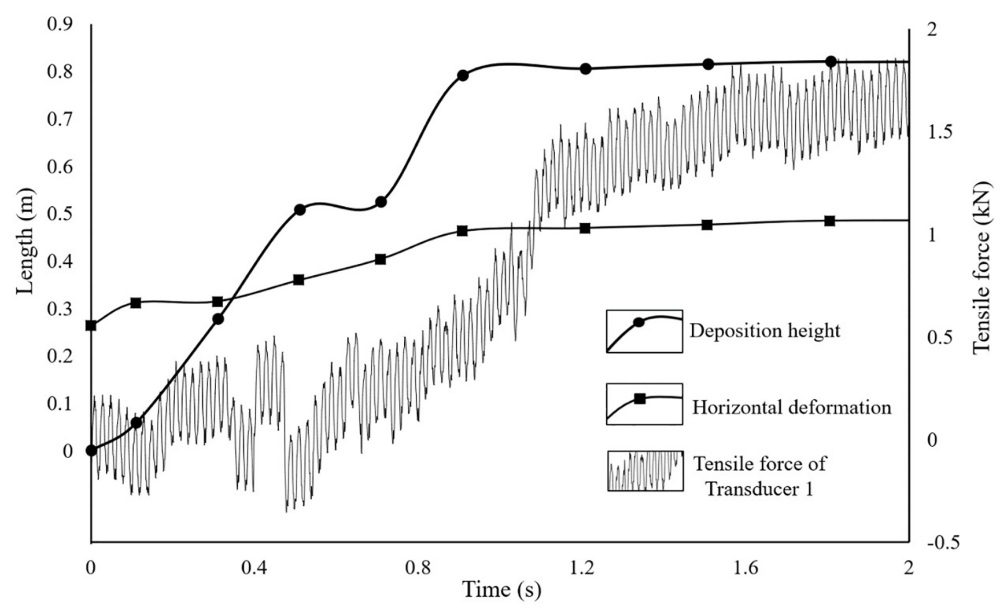

Figure 6. Relation between the deposition height of the granular flow, horizontal deformation of the flexible barrier, and tensile force of transducer 1 vs. time in test 1 .

which contains transducer $i$ and transducer $i+1$ is analysed and shown in Fig. 11. Thus, the impact force on the cross section can be calculated with the following equation:

$F_{\text {impact }, i, i+1}=F_{\text {tensile }, i} \cdot \cos \frac{\theta}{2}+F_{\text {tensile }, i+1} \cdot \cos \frac{\theta}{2}$,

where $F_{\text {tensile, } i}$ and $F_{\text {tensile, } i+1}$ are the maximum tensile forces on transducer $i$ and transducer $i+1$ installed in the measured area, $\theta$ is the included angle between the opposite transducers, and $F_{\text {impact }, i, i+1}$ is the calculated impact force on this cross section. Since the deformation in the measured area is assumed cone symmetric, $\theta$ is a constant in all cross sections formed by two opposite transducers. Thus, for the measured area with $n$ transducers, the maximum impact force, $F_{\text {measured }}$, can be calculated with the following equation:

$F_{\text {measured }}=\cos \frac{\theta}{2} \cdot \sum_{i=1}^{i=n} F_{\text {tensile }, i}$.

In our study, the maximum tensile forces on all transducers are measured and plotted in Fig. 12, and $\theta$ can be measured from the photograph taken at the moment of the largest deformation as shown in Fig. 13.

The impact pressure from the granular flow is assumed to be uniformly distributed in the cross-sectional area of the flume width multiplied by the height of the debris deposition, which covers the measured central area. The uniformly distributed impact loading on the flexible ring net has been proved by back-calculation using the tensile forces and deformations of the horizontal supporting cables of the flexible barrier in field tests (Wendeler et al., 2018). Combined with Eq. (4), the following equation is given to calculate the distributed impact loading on a flexible ring net:

$F_{\text {impact }}=F_{\text {measured }} \cdot \frac{A_{\text {impact }}}{A_{\text {measured }}}$

$$
=\cos \frac{\theta}{2} \cdot \sum_{i=1}^{i=n} F_{\text {tensile }, i} \cdot \frac{A_{\text {impact }}}{A_{\text {measured }}},
$$

where $A_{\text {impact }}$ and $A_{\text {measured }}$ represent the actual impact cross-sectional area and the measured central area in the test as shown in Fig. 12. All the parameters and calculated results are listed in Table 2.

\subsection{Calculation of loading reduction rate (LRR)}

The flexible ring net is supported by two posts that can rotate in the plane of the flow direction, and each post is supported by two inclined steel strand cables. Therefore, the impact force transferred from the flexible barrier to the supporting posts can be calculated from the tensile forces carried by the supporting cables in the direction of impact. Based on the symmetrical arrangement of the cables and the posts with respect to the flexible barrier, as plotted in Fig. 14a, the loading situations of the posts and the supporting cables located on both sides of the flexible barrier are also symmetrical when they are under a uniform impact pressure. Thus, the left post and its supporting cables, cable A left and cable B left, are selected as the analysis objects. The force analysis of the supporting cables is divided into two steps.

Firstly, forces on cable A left and cable B left are decomposed into components in the rotation plane of the post based on the top-view sketch (see Fig. 14a):

$F_{\mathrm{AL}, \mathrm{H}}=F_{\mathrm{AL}} \cdot \cos \alpha$,

$F_{\mathrm{BL}, \mathrm{H}}=F_{\mathrm{BL}} \cdot \cos \beta$,

where $F_{\mathrm{AL}}$ and $F_{\mathrm{BL}}$ are the measured maximum tensile forces on cable A left and cable B left during the impact, $F_{\mathrm{AL}, \mathrm{H}}$ and $F_{\mathrm{BL}, \mathrm{H}}$ are the components of $F_{\mathrm{AL}}$ and $F_{\mathrm{BL}}$ decomposed in the rotation plane of the left post, and $\alpha$ and $\beta$ are the included angles between cable A and Cable B and the rotation plane of the post. 

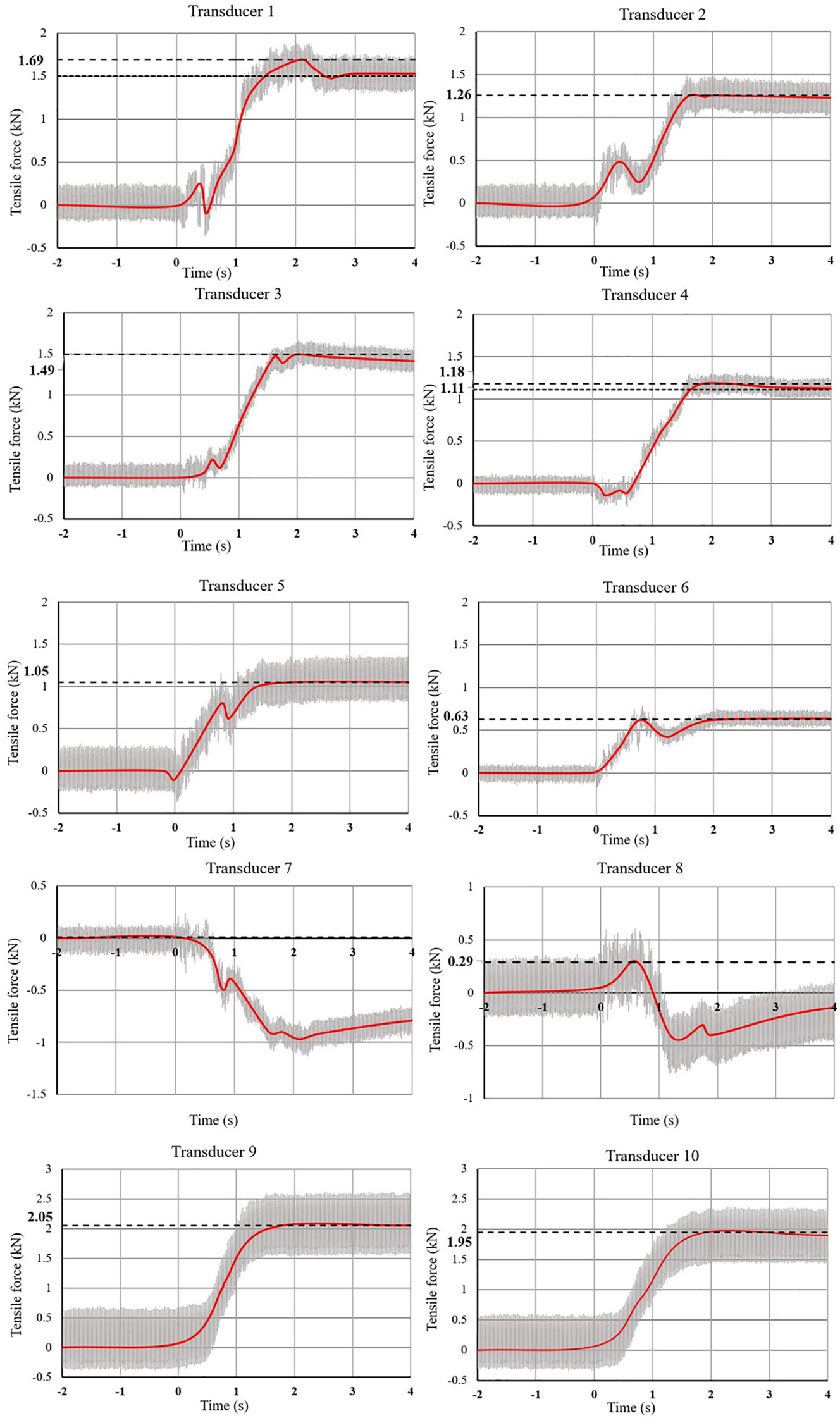

Figure 7. Recorded forces vs. time by the mini tension link transducers between rings in test 1 . 
(a)
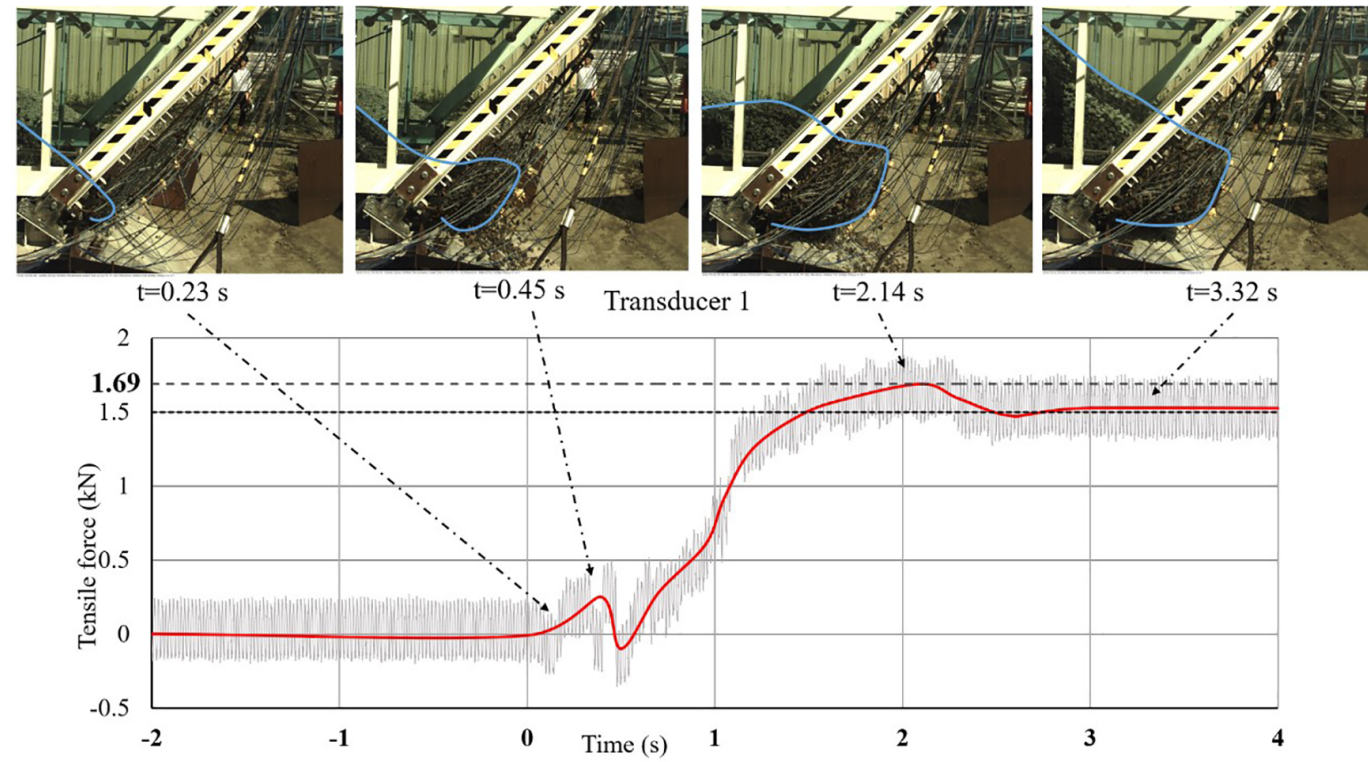

(b)
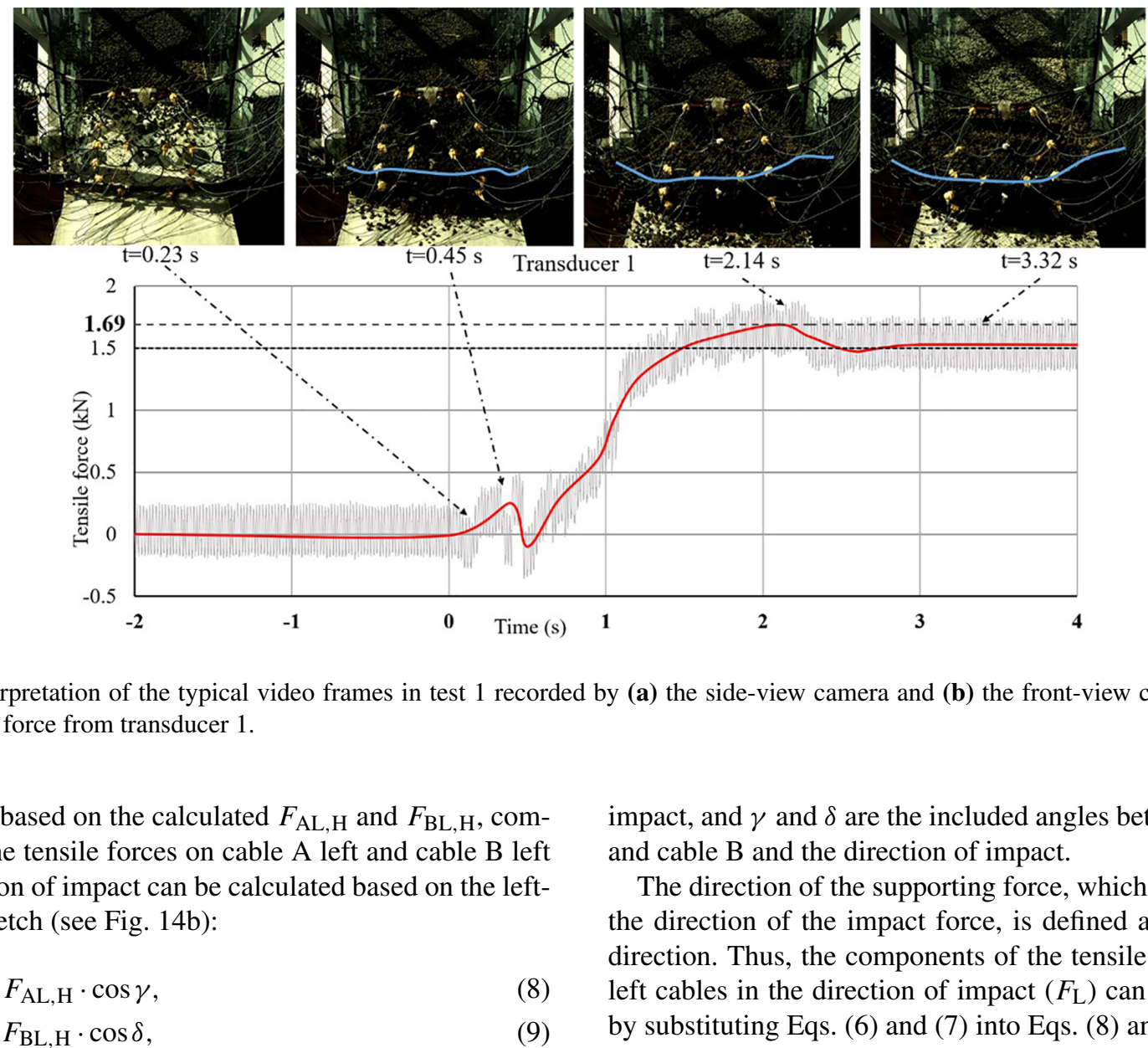

$F_{\mathrm{AL}, \mathrm{impact}}=F_{\mathrm{AL}, \mathrm{H}} \cdot \cos \gamma$,

$F_{\mathrm{BL}, \text { impact }}=F_{\mathrm{BL}, \mathrm{H}} \cdot \cos \delta$,

where $F_{\mathrm{AL} \text {,impact }}$ and $F_{\mathrm{BL} \text {,impact }}$ are the components of tensile forces on cable A left and cable B left in the direction of

impact, and $\gamma$ and $\delta$ are the included angles between cable A and cable $\mathrm{B}$ and the direction of impact.

The direction of the supporting force, which is opposite to the direction of the impact force, is defined as the positive direction. Thus, the components of the tensile forces on the left cables in the direction of impact $\left(F_{\mathrm{L}}\right)$ can be calculated by substituting Eqs. (6) and (7) into Eqs. (8) and (9):

$$
\begin{aligned}
F_{\mathrm{L}} & =F_{\mathrm{BL}, \text { impact }}-F_{\mathrm{AL}, \text { impact }}=F_{\mathrm{BL}, \mathrm{H}} \cdot \cos \delta-F_{\mathrm{AL}, \mathrm{H}} \cdot \cos \gamma \\
& =F_{\mathrm{BL}} \cdot \cos \delta \cdot \cos \beta-F_{\mathrm{AL}} \cdot \cos \gamma \cdot \cos \alpha .
\end{aligned}
$$



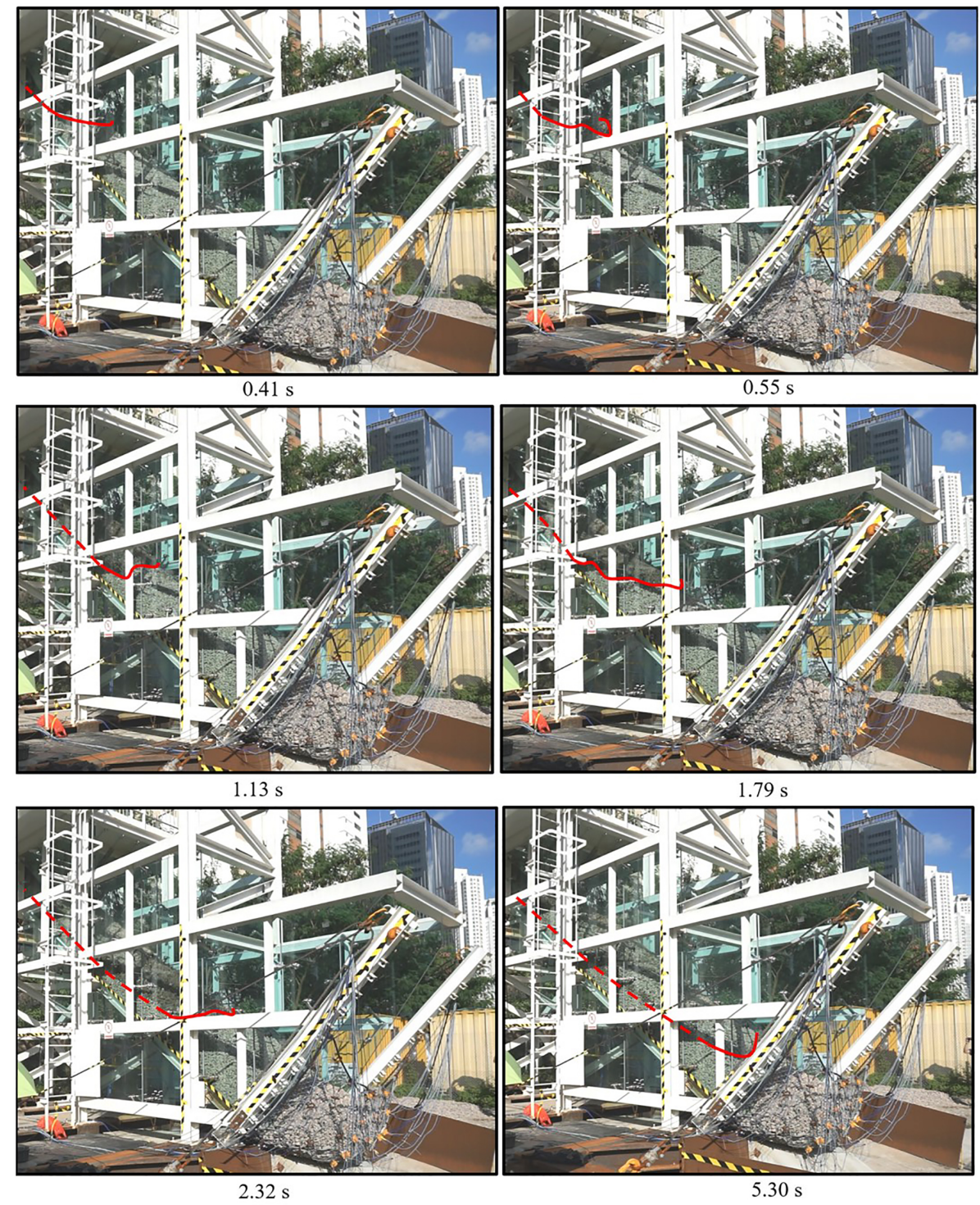

Figure 9. Motion of the granular flow in test 2.

Finally, based on the conservation of angular momentum and the symmetrical arrangement of the cables and the posts with respect to the flexible barrier, the equivalent impact force can be calculated from the tensile forces on the supporting cables with the following equation:

$$
\begin{aligned}
F_{\text {Cables, equivalent }} & =\frac{l_{\text {post }}}{l_{\text {impact }}}\left[\left(F_{\mathrm{BL}}+F_{\mathrm{BR}}\right) \cdot \cos \delta \cdot \cos \beta\right. \\
& \left.-\left(F_{\mathrm{AL}}+F_{\mathrm{AR}}\right) \cdot \cos \gamma \cdot \cos \alpha\right],
\end{aligned}
$$

where $F_{\text {Cables,equivalent }}$ is the equivalent impact force calculated from the tensile forces on the supporting cables, and $l_{\text {post }}$ is the distance between the rotation fulcrum of the post and the connecting point of the cables, $l_{\text {impact }}$ is the distance between the rotation fulcrum of the post and the equivalent impact height of the granular flow. $F_{\mathrm{AL}}, F_{\mathrm{AR}}, F_{\mathrm{BL}}$, and
$F_{\mathrm{BR}}$ are the measured maximum tensile forces on the supporting cables. Their values are presented in Fig. 13. All parameters, as well as the calculated results, are listed in Table 2 .

It is found that flexibility of flexible barriers makes an obvious contribution to the reduction of the impact loading from a debris flow (Volkwein, 2014; Song et al., 2017). Since almost all the debris material was trapped in this study, the load reduction is mainly attributed to the large deformation of the flexible ring net during the impact. To quantify the contribution of flexibility to impact loading reduction, the loading reduction rate (LRR) of the flexible barrier is defined as

$\mathrm{LRR}=\frac{F_{\text {impact }}-F_{\text {Cables, equivalent }}}{F_{\text {impact }}} \cdot 100 \%$. 


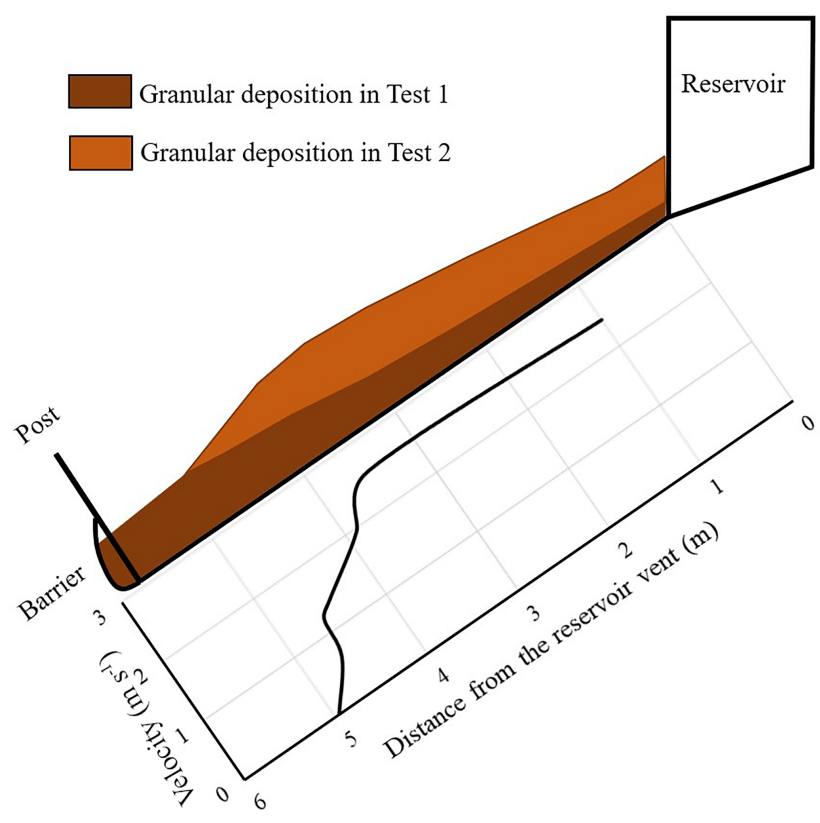

Figure 10. Side profile of the depositions in test 1 and test 2 and the velocity change of the granular flow in test 2 with the moving distance.

LRR in the granular flow tests is calculated and presented in Table 2. It is found that around $28 \%$ of the impact loading from the dry granular flow in test 1 was attenuated by the flexible barrier.

\subsection{Comparison of simple approaches with measured impact forces}

Two widely accepted simple approaches for impact force estimation, the hydro-dynamic approach and hydro-static approach (Kwan and Cheung, 2012; Volkwein, 2014; Song et al., 2017; Ashwood and Hungr, 2016; Wendeler, 2008; Wendeler et al., 2018), are compared in this section to validate their applications in the design of flexible barriers. To quantify the accuracies of the simple approaches, relative error (RE) is usually defined as

$\mathrm{RE}=\left|\frac{F_{\text {calculated }}-F_{\text {measured }}}{F_{\text {measured }}}\right| \times 100 \%$,

where $F_{\text {calculated }}$ represent the calculated impact force of the simple approach, which is obtained by integrating the parameters listed in Tables 1 and 2 into the hydro-dynamic and hydro-static approaches listed in Table 3. In the table, two dynamic coefficients suggested by Wendeler (2008) -0.7 for mud flow, 2.0 for granular flow, and a static coefficient of 1.0 - are utilized. $F_{\text {measured }}$ is the measured impact force on different components of the flexible barrier.

The calculated results are validated using the measured impact forces on the flexible ring net and on the supporting structures. The validation results are quantified with the
Table 2. Values of measured parameters and calculated results in test 1 .

\begin{tabular}{lr}
\hline Parameters and results & Values \\
\hline Moving speed $\left(\mathrm{m} \mathrm{s}^{-1}\right)$ & 5 \\
Included angle $\theta\left(^{\circ}\right)$ & 130 \\
$A_{\text {measured }}\left(\mathrm{m}^{2}\right)$ & 0.644 \\
$A_{\text {impact }}\left(\mathrm{m}^{2}\right)$ & 1.44 \\
$i=n$ & \\
$\sum_{i=1} F_{\text {tensile }, i}(\mathrm{kN})$ & 11.59 \\
$F_{\text {measured }}(\mathrm{kN})$ & \\
$l_{\text {impact }}(\mathrm{m})$ & 4.9 \\
$l_{\text {post }}(\mathrm{m})$ & 0.242 \\
$h(\mathrm{~m})$ & 2.7 \\
$h_{\text {deposit }}(\mathrm{m})$ & 0.086 \\
$\alpha\left(^{\circ}\right)$ & 0.82 \\
$\beta\left(^{\circ}\right)$ & 62 \\
$\gamma\left(^{\circ}\right)$ & 24 \\
$\delta\left(^{\circ}\right)$ & 76 \\
$F_{\mathrm{AL}}(\mathrm{kN})$ & 60 \\
$F_{\mathrm{AR}}(\mathrm{kN})$ & 0.062 \\
$F_{\mathrm{BL}}(\mathrm{kN})$ & 0.062 \\
$F_{\mathrm{BR}}(\mathrm{kN})$ & 0.79 \\
$F_{\mathrm{Cables}, \text { equivalent }}(\mathrm{kN})$ & 0.79 \\
$F_{\text {impact }}(\mathrm{kN})$ & 7.89 \\
Loading reduction rate $(\mathrm{LRR})(\%)$ & 28.01 \\
\hline
\end{tabular}

value of relative error. The results of the calculation and the validation are listed in Table 3. Compared with the measured impact force on the flexible ring net directly, the hydrodynamic approach with the dynamic coefficient of 2.0 has the best performance in estimating the impact force on the flexible ring net with a small deviation of $5.8 \%$, which verifies the dynamic coefficient suggested by Wendeler (2008) for granular flows. The reduced dynamic coefficient of 0.7 for debris flows with lower densities (lower than $1900 \mathrm{~kg} \mathrm{~m}^{-3}$ ), on the other hand, obviously underestimated the loading on the flexible ring net by $50 \%$. The reduction of the dynamic coefficient takes account of the dewatering and penetration of small particles during the impact based on lab tests and field observations (Wendeler, 2008; Wendeler and Volkwein, 2015; Wendeler et al., 2018). Therefore, the underestimation of the impact loading could be attributed to all of the trapped granular material by the secondary mesh net in our dry-granular-flow impact tests based on the observations of the impact process with the high-speed cameras. In contrast, the hydro-static approach with the static coefficient of 1.0 fits quite well with the measured impact force on the supporting structures. This is reasonable since part of the dynamic impact from the granular flow can be attenuated by the flexible ring net, and the static loading can be fully transferred to the supporting structures. This phenomenon is also proved by the gradually increased tensile forces on cable B left and cable B right shown in Fig. 13b. Thus, in the design of a flexible bar- 
Table 3. Comparisons of the calculated impact forces using simple approaches with the measured impact forces on different components of a flexible barrier in test 1 .

\begin{tabular}{lrrr}
\hline $\begin{array}{l}\text { Simple approaches for } \\
\text { impact force estimation }\end{array}$ & $\begin{array}{r}\text { Calculated } \\
\text { impact } \\
\text { force }(\mathrm{kN})\end{array}$ & $\begin{array}{r}\text { RE with impact } \\
\text { force on the } \\
\text { flexible net }(\%)\end{array}$ & $\begin{array}{r}\text { RE with impact force } \\
\text { on the supporting } \\
\text { structures }(\%)\end{array}$ \\
\hline $\begin{array}{l}F_{\text {impact }}=10.96 \mathrm{kN} \\
F_{\text {calculated }}=\alpha \rho_{\text {bulk }} v_{0}^{2} h w \\
\text { (hydro-dynamic }\end{array}$ & 3.61 & 67.1 & $F_{\text {Cables,equivalent }=7.89 \mathrm{kN}}$ \\
approach with $\alpha=0.7)$ \\
(for muddy debris flows \\
with lower densities) \\
(Wendeler, 2008)
\end{tabular}

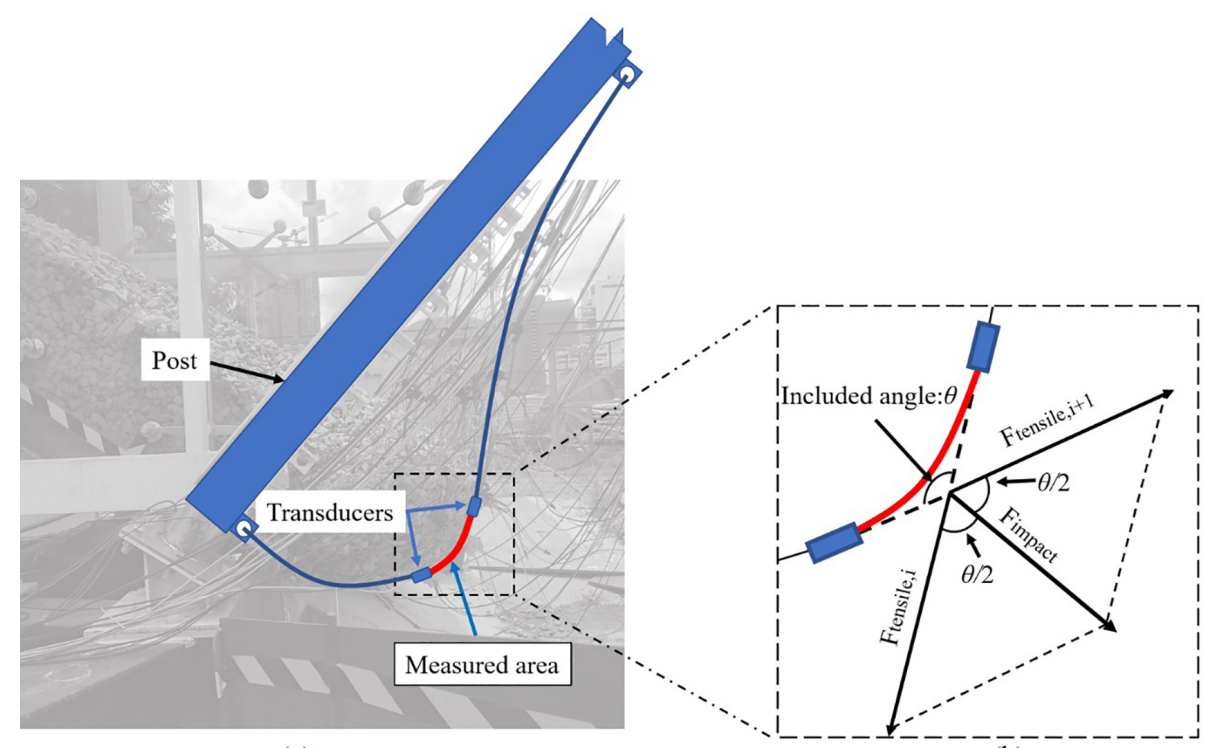

(a)

(b)

Figure 11. (a) Sketch of the flexible barrier under the impact of a granular flow and (b) the simplified force analysis of the measured area in the cross section of transducer $i$ and transducer $i+1$.

rier for debris flow mitigation, the hydro-dynamic approach and the hydro-static approach can be used in the design and the selection of the flexible ring net and the supporting structures, respectively. Even though the dynamic coefficients and the static coefficient are verified by the data of large-scale tests in this study, more tests are required to further verify and select suitable coefficients before they can be used in the design. 


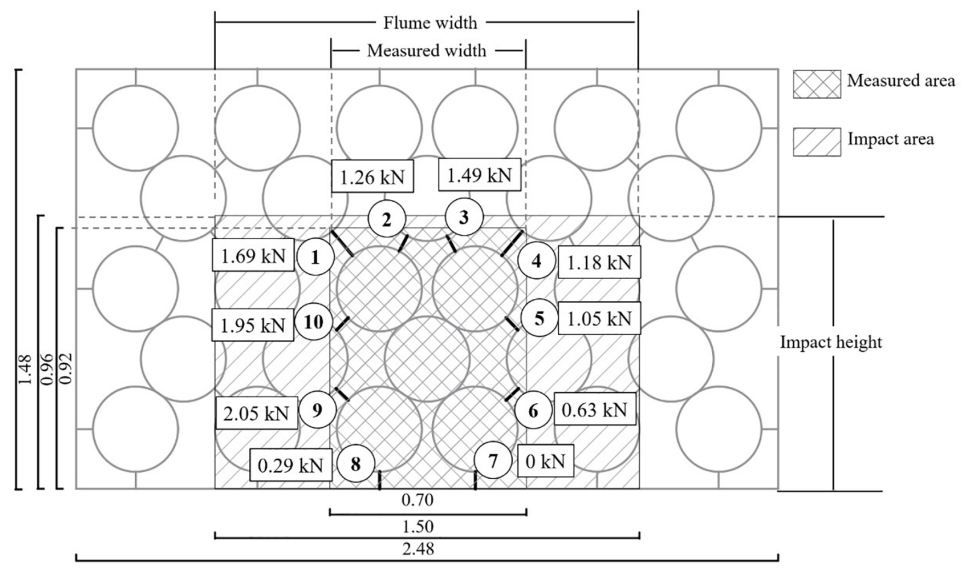

Figure 12. Sketch of the impact and measured area in test 1 and the maximum tensile forces measured from 10 mini tension link transducers under the impact of the granular flow (unit: $\mathrm{m}$ ).

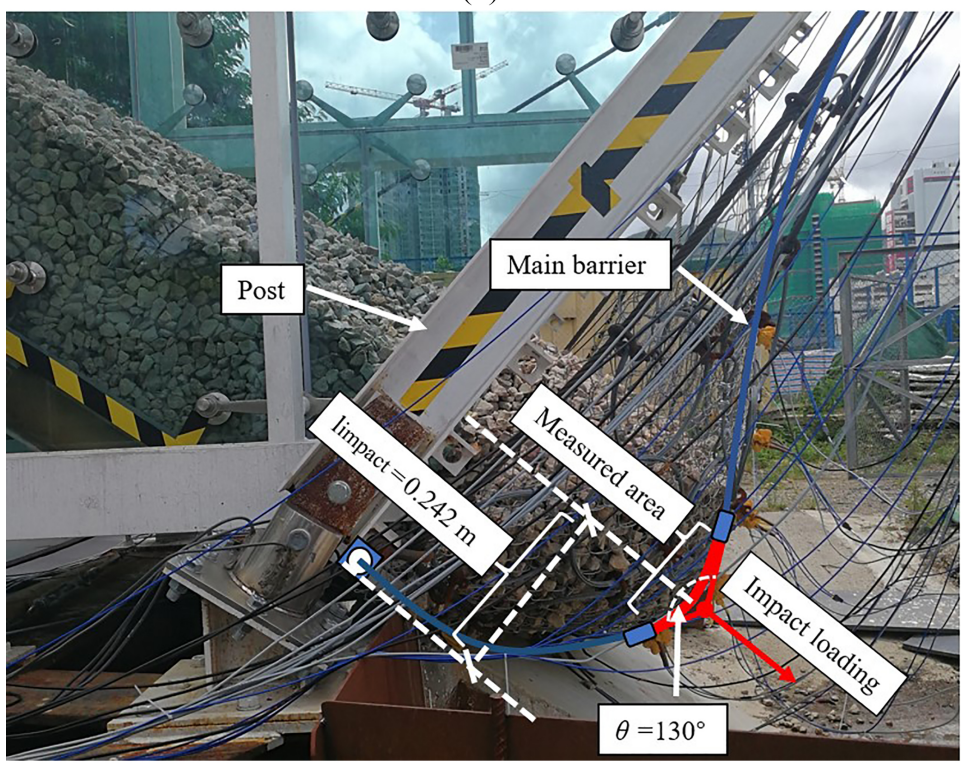

(b)
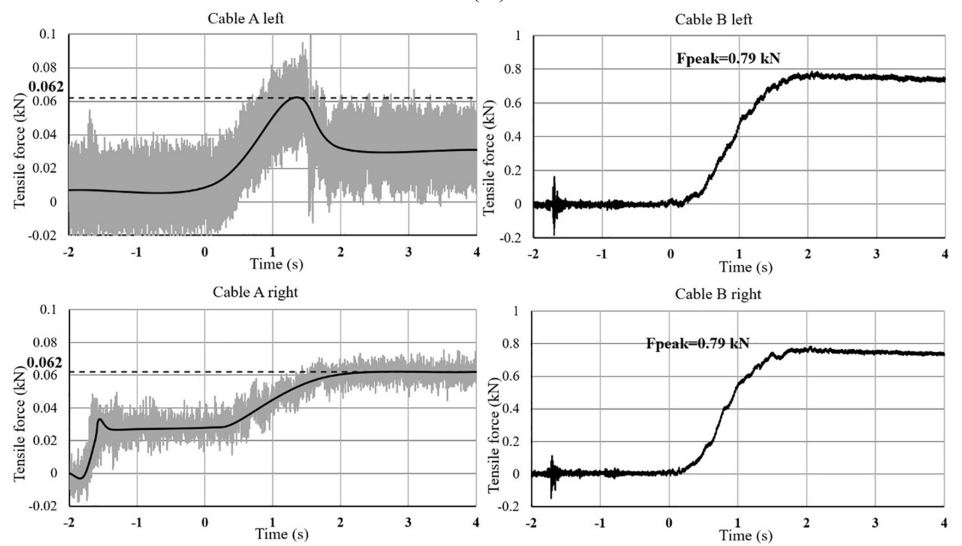

Figure 13. (a) Photograph at the instant of the largest deformation with measured parameters and (b) recorded forces and time by the tension link transducers on the supporting cables in test 1 . 
(a)

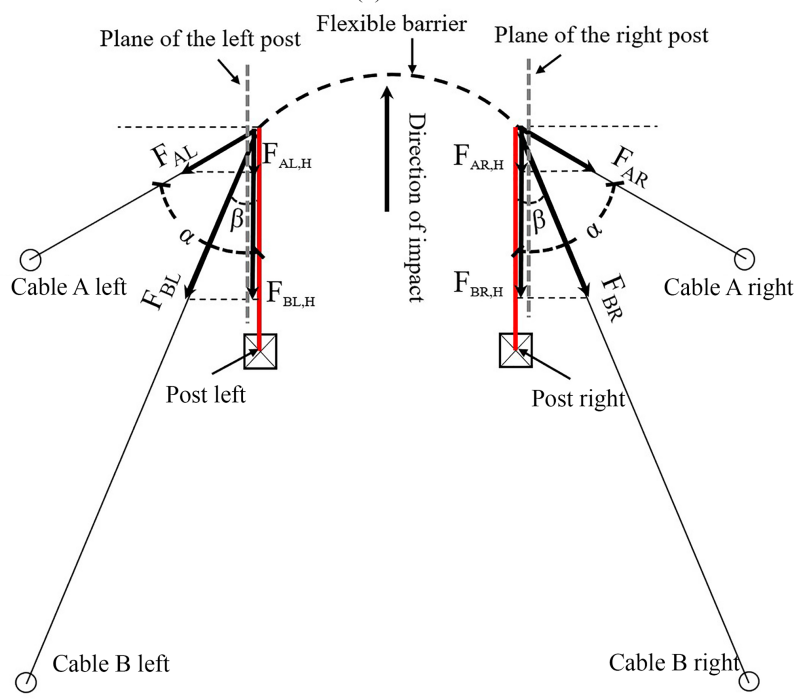

(b)

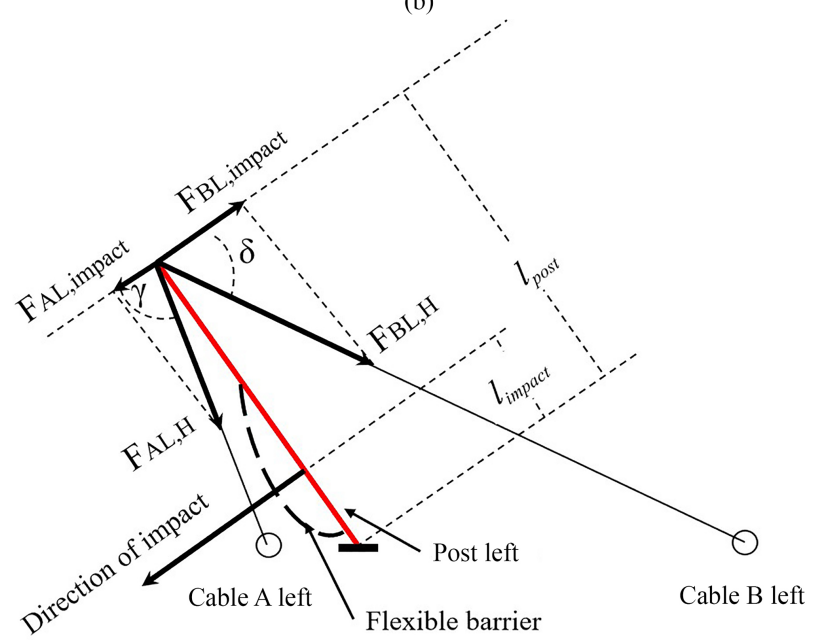

Figure 14. (a) Top view and (b) left-side view of sketches with the force analysis of the posts and cables.

\section{Conclusions}

In this paper, an improved large-scale physical modelling facility for debris flow research and a well-arranged highfrequency measurement system are introduced. Using this device, two tests were performed to study the behaviour of a flexible barrier subjected to the impacts of granular flows. From the experimental data and their analysis, key findings and conclusions are summarized and presented as below:

a. In test 1 , the front of the granular flow impacted the flexible ring net directly, was deposited behind the barrier layer by layer, and formed a deposition wedge in the first second. After $1.0 \mathrm{~s}$, the following granular flow was deposited behind the deposition wedge.

b. The static loading and the dynamic loading co-existed in the impact process, and the static loading was dominant.
The static loading is attributed to the gradual deposition of aggregate, and the dynamic loading was caused by the impact of the debris front. The granular front that arrived later applied impact loading on the flexible barrier via the deposition wedge. With the deposition of aggregate, the stationary debris formed a cushion behind the barrier and attenuated all the impact loading from the following granular front.

c. In test 2, the second granular flow in a multiple-flow event was performed. The velocity and the flow depth of the granular flow decreased during movement, and the front stopped before it could reach the flexible barrier due to the large basal friction between the moving granular flow and the granular deposition and the poor fluidity of the dry granular flow.

d. The impact loading on a flexible ring net was directly measured from the tensile forces in the central area of the flexible ring net. In test 1 , the measured maximum impact force on the flexible ring net was $10.96 \mathrm{kN}$.

e. The contribution of flexibility to impact loading reduction is quantified by introducing the loading reduction rate (LRR). By calculating the impact loading transferred to the supporting structures, it can be concluded that almost $28 \%$ of the impact loading from the granular flow was attenuated by the flexible ring net.

f. From the comparisons of the hydro-dynamic approach and the hydro-static approach with the measured impact forces on different components, it is found that the hydro-dynamic approach with the dynamic coefficient of 2.0 fits well with the measured impact force on the flexible ring net, and the hydro-static approach with the static coefficient of 1.0 has a good performance in estimating the impact force on the supporting structures.

With the conclusions drawn from the large-scale tests in this paper, it can be found that the impact force on the flexible ring net and the impact force on the supporting structures are different due to the large deformation of the flexible ring net; thus the loadings on them should be estimated separately. By applying the LRR and suitable impact loading estimation approaches (see the verification results plotted in Table 3), the impact forces on the flexible ring net and on the supporting structures can be estimated. Thus, the design of a flexible barrier for debris flow mitigation can be optimized by dimensioning and designing different components with differently designed loadings, which provides a safer and more economical design method. The particle size distribution of aggregates used in this study is relatively uniform (see Fig. 4). Natural soil usually contains fine material to some extent. In the future, the tests of rapid debris flows will be conducted to investigate the behaviour of debris flows and examine the performance of a flexible barrier under the impact of rapid debris flows. 
Data availability. Most data used in this paper have been plotted in relevant figures. The rest of the data are not publicly available because of restrictions by the funding organizations. However, if readers or researchers are interested in using our test data, they are welcome to contact the corresponding author Jian-Hua Yin (cejhyin@polyu.edu.hk) of this paper directly.

Author contributions. The study was conceived by DYT and JHY, and the methodology was designed with the contribution of all authors. DYT, JQQ, and ZHZ obtained the data and carried out the data analysis. DYT prepared the first version of the manuscript with the guidance of JHY and WQF. All authors discussed the results and contributed to editing the final version of the article.

Competing interests. The authors declare that they have no conflict of interest.

Acknowledgements. The authors acknowledge the financial support from the Research Institute for Sustainable Urban Development of The Hong Kong Polytechnic University (PolyU). The work in this paper is also supported by a National State Key Project "973" grant (grant no. 2014CB047000) (sub-project no. 2014CB047001) from the Ministry of Science and Technology of the People's Republic of China, a CRF project (grant no. PolyU12/CRF/13E) from the Research Grants Council (RGC) of the Hong Kong Special Administrative Region Government of China. The financial support from PolyU grants (1-ZVCR. 1-ZVEH. 4-BCAU, 4-BCAW, 4-BCB1, $5-\mathrm{ZDAF})$ is acknowledged. This paper is also supported by the Research Centre for Urban Hazards Mitigation of the Faculty of Construction and Environment of PolyU.

Edited by: Perry Bartelt

Reviewed by: two anonymous referees

\section{References}

Arattano, M. and Marchi, L.: Measurements of debris flow velocity through cross-correlation of instrumentation data, Nat. Hazards Earth Syst. Sci., 5, 137-142, https://doi.org/10.5194/nhess5-137-2005, 2005.

Armanini, A.: On the dynamic impact of debris flows, in: Recent developments on debris flows, edited by: Armanini, A. and Michiue, M., 208-226, Springer, Berlin, Heidelberg, 1997.

Ashwood, W. and Hungr, O. Estimating total resisting force in flexible barrier impacted by a granular avalanche using physical and numerical modeling, Can. Geotech. J., 53, 1700-1717, 2016.

ASTM: ASTM C29/C29M-17, Standard Test Method for Bulk Density (Unit Weight) and Voids in Aggregate, ASTM International, West Conshohocken, PA, available at: www.astm.org (last access: 26 September 2018), 2017.

Berti, M., Genevois, R., Simoni, A. and Tecca, P.R. Field observations of a debris flow event in the Dolomites. Geomorphology, 29(3-4), 265-274, 1999.
Bugnion, L., McArdell, B. W., Bartelt, P., and Wendeler, C.: Measurements of hillslope debris flow impact pressure on obstacles, Landslides, 9, 179-187, 2012.

Canelli, L., Ferrero, A. M., Migliazza, M., and Segalini, A.: Debris flow risk mitigation by the means of rigid and flexible barriers - experimental tests and impact analysis, Nat. Hazards Earth Syst. Sci., 12, 1693-1699, https://doi.org/10.5194/nhess12-1693-2012, 2012.

Chen, H. X., Zhang, L. M., Gao, L., Yuan, Q., Lu, T., Xiang, B., and Zhuang, W. L.: Simulation of interactions among multiple debris flows, Landslides, 14, 595-615, 2017.

Cui, P., Zeng, C., and Lei, Y.: Experimental analysis on the impact force of viscous debris flow, Earth Surf. Proc. Land., 40, 1644$1655,2015$.

DeNatale, J. S., Iverson, R. M., Major, J. J., LaHusen, R. G., Fiegel, G. L., and Duffy, J. D.: Experimental testing of flexible barriers for containment of debris flows, US Department of the Interior, US Geological Survey, Vanvcouver, Washington, US, 1999.

Hu, K., Wei, F., Hong, Y., and Li, X.: Field measurement of impact force of debris flow. Yanshilixue Yu Gongcheng Xuebao, Chinese Journal of Rock Mechanics and Engineering, 25, 28132819, 2006.

Hungr, O.: A model for the runout analysis of rapid flow slides, debris flows, and avalanches, Can. Geotech. J., 32, 610-623, 1995.

Hungr, O., Morgan, G. C., and Kellerhals, R.: Quantitative Analysis of Debris Torrent Hazards for Design of Remedial Measures, Can. Geotech. J., 21, 663-677, https://doi.org/10.1139/t84-073, 1984.

Hutter, K. and Koch, T.: Motion of a granular avalanche in an exponentially curved chute: experiments and theoretical predictions, Philos. T. Roy. Soc. Lond. A, 334, 93-138, 1991.

Ishikawa, N., Inoue, R., Hayashi, K., Hasegawa, Y., and Mizuyama, T.: Experimental approach on measurement of impulsive fluid force using debris flow model, 26-30 May 2008, Dornbirn Vorarlberg Austria, INTERPRAEVENT 2008, Conference Proceedings, 1, 343-354, 2008.

Iverson, R. M.: Scaling and design of landslide and debris-flow experiments, Geomorphology, 244, 9-20, 2015.

Iverson, R. M., Logan, M., LaHusen, R. G., and Berti, M. The perfect debris flow? Aggregated results from 28 largescale experiments, J. Geophys. Res.-Ea. Surf., 115, F03005, https://doi.org/10.1029/2009JF001514, 2010.

Kwan, J. S. H. and Cheung, R. W. M.: Suggestions on design approaches for flexible debris-resisting barriers, Discussion Note No. DN 1/2012, Geotechnical Engineering Office, Hong Kong, 90 pp., 2012.

Kwan, J. S. H., Chan, S. L., Cheuk, J. C. Y., and Koo, R. C. H.: A case study on an open hillside landslide impacting on a flexible rockfall barrier at Jordan Valley, Hong Kong, Landslides, 11, 1037-1050, 2014.

Lichtenhahn, C.: Die Berechnung von Sperren in Beton und Eisenbeton [Die design of barriers made of concrete and reinforced concrete], Kolloquium über Wildbachsperren, Heft 102, Mitteilungen der Forstlichen Bundesanstalt Wien, Wien, Germany, 91-127, 1973.

Miura, K., Maeda, K., and Toki, S.: Method of measurement for the angle of repose of sands, Soils Foundat., 37, 89-96, 1997.

Paik, J., Son, S., Kim, T., and Kim, S.: A real-scale field experiment of debris flow for investigating its deposition and entrainment, 
in: AGU Fall Meeting Abstracts, 3-7 December 2012, San Francisco, 2012.

Prochaska, A. B., Santi, P. M., Higgins, J. D., and Cannon, S. H.: A study of methods to estimate debris flow velocity, Landslides, 5, 431-444, 2008

Rankine, W.: On the stability of loose earth, Philos. T. Roy. Soc. Lond., 147, 9-27, 1857.

Santi, P. M., Hewitt, K., VanDine, D. F., and Cruz, E. B.: Debrisflow impact, vulnerability, and response, Nat. Hazards, 56, 371402, 2011.

Song, D., Choi, C. E., Ng, C. W. W., and Zhou, G. G. D.: Geophysical flows impacting a flexible barrier: effects of solid-fluid interaction, Landslides, 15, 99-110, 2017.

Su, L. J., Xu, X. Q., Geng, X. Y., and Liang, S. Q.: An integrated geophysical approach for investigating hydro-geological characteristics of a debris landslide in the Wenchuan earthquake area, Eng. Geol., 219, 52-63, 2017.

Takahashi, T.: Debris flow: mechanics, prediction and countermeasures, CRC Press, London, 2014.

Volkwein, A.: Flexible debris flow barriers, in: Design and application, WSL Berichte, Swiss Federal Institute for Forest, Snow and Landscape Research WSL, Birmensdorf, 29 pp., 2014.

Volkwein, A., Wendeler, C., and Guasti, G.: Design of flexible debris flow barriers, in: 5th International Conference debris-flow hazard mitigation, Mechanics, prediction and assessment, Padua, Italy, 1093-1100, 2011.

Wendeler, C. and Volkwein, A. Laboratory tests for the optimization of mesh size for flexible debris-flow barriers, Nat. Hazards Earth Syst. Sci., 15, 2597-2604, https://doi.org/10.5194/nhess15-2597-2015, 2015.
Wendeler, C., McArdell, B. W., Rickenmann, D., Volkwein, A., Roth, A., and Denk, M.: Field testing and numerical modeling of flexible debris flow barriers, in: Proceedings of international conference on physical modelling in geotechnics, Hong Kong, 2006.

Wendeler, C., Volkwein, A., Roth, A., Denk, M., and Wartmann, S.: Field measurements and numerical modelling of flexible debris flow barriers, in: Debris-Flow Hazards Mitig. Mech. Predict. Assess., Millpress, Rotterdam, 681-687, 2007.

Wendeler, C., Volkwein, A., McArdell, B. W., and Bartelt, P.: Load model for designing flexible steel barriers for debris flow mitigation, Can. Geotech. J., https://doi.org/10.1139/cgj-2016-0157, 2018.

Wendeler, C. S. I.: Murgangrückhalt in Wildbächen. Grundlagen zu Planung und Berechnung von flexiblen Barrieren, PhD thesis, ETH, Zurich, 2008.

WSL: Report on testing SL-100 a protection system against shallow landslides, Technical Report 1-24, WSL, Birmensdorf, 2010.

Xu, Q., Zhang, S., Li, W. L., and Van Asch, T. W.: The 13 August 2010 catastrophic debris flows after the 2008 Wenchuan earthquake, China, Nat. Hazards Earth Syst. Sci., 12, 201-216, https://doi.org/10.5194/nhess-12-201-2012, 2012.

Yagi, H., Sato, G., Higaki, D., Yamamoto, M., and Yamasaki, T. Distribution and characteristics of landslides induced by the Iwate-Miyagi Nairiku earthquake in 2008 in Tohoku District, Northeast Japan, Landslides, 6, 335-344, 2009.

Zhou, G. G., Ng, C. W., and Sun, Q. C.: A new theoretical method for analyzing confined dry granular flows, Landslides, 11, 369384, 2014. 